\title{
IMPACT OF ORAL HEALTH BEHAVIOURS ON DENTAL CARIES IN CHILDREN WITH CEREBRAL PALSY: A CASE-CONTROL STUDY
}

\author{
Sara M. Quritum ${ }^{1}$ BDS, Karin M. Dowidar ${ }^{2}$ PhD, Amel M. Ahmed ${ }^{3}$ PhD, Tarek E. Omar ${ }^{4}$ Phd.
}

\begin{abstract}
INTRODUCTION: Dental caries is consistently reported as one of the primary medical needs of children with Cerebral palsy (CP). It has negative impact on the overall health of these children and increase burden on their parents

OBJECTIVES: The aim of the study was to assess the influence of socio-economic profile, previous dental visits, oral hygiene practices, and dietary habits on dental caries experience in children with CP in Alexandria, Egypt.

MATERIALS AND METHODS: This case control study included 80 children with CP, who were 3 to 11 years old. Equal number of cases (children with CP who had caries lesions) and controls (caries free children with CP) were included. Data were collected using an interview based questionnaire and clinical examination. Questionnaire assessed socio-economic characteristics, medical history, previous dental visits, oral health behaviours and dietary habits. Clinical examination assessed caries experience and oral hygiene index (OHI-S). Multiple regression analysis was used to examine the factors associated with dental caries.

RESULTS: The average age of children in the study was 6.75 years, $68.8 \%$ of them were males. Caries experience was expressed through $\mathrm{dmft}$ for the primary teeth and dft/DMFT for mixed dentition. The mean values were $6.72 \pm 2.52,5.64 \pm 2.98$ and $1.32 \pm 1.73$, respectively. Children with CP with caries lesions had statistically significant poorer oral hygiene $(\mathrm{p}<0.0001)$, which is highly associated with high caries experience (Regression Coefficient $=4.45,95 \% \mathrm{CI}=3.75,5.14$ ). Other factors associated with DMF in children with CP included daily sugary snaking habits and food consistency.

CONCLUSIONS: The level of oral hygiene status reflecting the efficiency of oral health behaviours, is considered the main factor associated with caries experience in children with CP. However, eating solid food and less than two sugary snacks per day were considered caries protective factors.

KEYWORDS: Cerebral palsy, caries, plaque, oral health behaviours, oral hygiene, dietary habits.
\end{abstract}

1- B.D.S. Faculty of Dentistry, Alexandria University, Egypt. Instructor, Department of Pediatric Dentistry and Dental Public Health, Faculty of Dentistry,

Alexandria University, Egypt.

2- Professor of Pediatric Dentistry, Department of Pediatric Dentistry and Dental Public Health, Faculty of Dentistry, Alexandria University, Egypt.

3- Assoc. Professor of Pediatric Dentistry, Department of Pediatric Dentistry and Dental Public Health, Faculty of Dentistry, Alexandria University, Egypt.

4- Professor of Neurology, Department of Pediatrics, Faculty of Medicine, Alexandria University, Egypt.

Corresponding author:

E-mail: sara.quritum@gmail.com

\section{INTRODUCTION}

Cerebral palsy (CP) is the most common \& the most severe form of neuromuscular disability affecting children (1). Prevalence of CP has been found to rise in the last 40 years (2). Its global prevalence was reported in 2013 to be 2.1 per 1000 live births (3).

Cerebral palsy describes a heterogeneous group of permanent disorder affecting movement and posture development, which are attributed to non-progressive brain injury (1). The main etiological factor is the lack of oxygenation of the brain cells in pre-, peri- or post-natal period, affecting the central nervous system structure and function in the maturation phase (4). Trauma, infection, hyperbilirubinaemia, in addition to biochemical and genetic factors may be also considered risk factors for this systemic condition (5).

A wide range of oral health problems are reported in children with CP, owing to structural changes in the orofacial region and para-functional oral habits associated with the neuromuscular deficits (1). These may include dental and facial trauma, developmental enamel defects, erosive tooth wear, dental caries, and periodontal diseases (6-8).

The literature presents conflicting data related to the prevalence of dental caries and its associated risk factors among individuals with disabilities. Some authors reported increased prevalence of dental caries (9-12), while others found a lower prevalence than in populations without CP (13). However, Pope and Curzon noted that children with CP do not normally exhibit

increased dental caries when compared with healthy, agematched controls

These results are inconclusive and tend to differ between countries (1).

Dental caries constitutes a multifactor disease in which different biological, economic, cultural, environmental and social factors interact (15). Oral hygiene is considered the main predisposing factor in the development of dental caries; a fact that is widely discussed in the literature (16). The disorganization of biofilms, accompanied by the application of topical fluoride, remains one of the most effective individual procedures for the control of dental caries (17).

High caries prevalence in these children may be also explained by poor masticatory muscular control that encourages consumption of mushy food, food stagnation in the buccal and labial sulci and reduced self-cleansing function in the oral cavity (18). 
Santos MT et al. (19) evaluated the inter-relationship between caries experience, oro-motor dysfunction, age, and dietary consistency in individuals with CP. It was reported that the highest total DMFT values were measured for individuals who were severely impaired and also the youngest, as well as for those receiving liquid diets.

The influence of oral health behaviours on the caries experience in children with intellectual disabilities was evaluated in a cross-sectional study done by Liu Z et al. (20) in China. They found that the presence of cerebral palsy contributed to an increase risk of caries experience in intellectually disabled children, while tooth brushing more than twice a day and routine dental visits were cariesprotective factors.

A com $\neg$ munity-based case-control study done by Rennan Y. Du (21) in Hong Kong comparing oral health behaviours of preschool children with and without $\mathrm{CP}$ and to assess oral health knowledge and attitudes of their primary caregivers. It was concluded that primary caregivers of children of both groups had similar oral health knowledge and attitudes. However, differences in oral health behaviours existed between them; particu $\neg$ larly with respect to dental attendance.

The prevalence and factors associated with dental caries and periodontal disease was assessed in Brazilian children and adolescents with cerebral palsy. The effect of demographic, socioeconomic and oral health behavioural variables were examined. It was reported that the caregiver's educational level of less than eight years was associated with higher dental caries experience (11).

Dental caries could have negative impact on the overall health of children with cerebral palsy and increase burden on their parents (22), however only few studies had discussed caries experience and its predisposing factors in these children. The objective of the present case control study was to determine the effect of socio-economic profile, previous dental visits, oral hygiene practices, and dietary habits on dental caries experience in children with CP in Alexandria, Egypt. The hypothesis to be tested in the study that differences could exist between children with CP who had caries and who were caries free, regarding the oral health behaviours.

\section{MATERIALS AND METHODS}

Ethical approval for the study was obtained from the Dental Research Ethics Committee, Faculty of Dentistry, Alexandria University. Parents/ caregivers of all children were asked to provide an informed written consent for examination and publication, after thorough explanation of the study aims.

This case- control analytical study was conducted in Alexandria, Egypt, in the period from 2016 to 2017. Children with CP were recruited from Alexandria University Children's Hospital (AUCH) and its outpatientclinics (Paediatric Neurology and Physical Medicine), from Paediatric Dental Clinic in the Department of Paediatric Dentistry and Dental Public Health, Faculty of Dentistry, Alexandria University, and from governmental and private institutions for children with special needs.

The assumptions made for sample size estimation based on proportion of tooth brushing frequency in children with CP who had carious lesion (26\%) and who were caries free $(74 \%)(11)$, alpha error $=5 \%$ and beta error $=20 \%$. Using MedCalc software (MedCalc Software, Mariakerke,
Belgium), the estimated sample size was about 25 children per group as minimum. In the present study 40 subject were enrolled into each group.

The studied population included 80 children with CP, ranged from 3-11 years old. These children had a medical diagnosis of cerebral palsy assigned by a paediatrician or neurologist as documented in patient's files. Children who had any other medically compromising condition, severely uncooperative or didn't get parental consent were excluded from the study. The study population was allocated into two main groups according to the caries activity, cases were children with CP who had dmft/

DMFT $>0$, while dmft/ DMFT equals zero in the control group. Both groups were age and sex matched.

Data were collected using the following methods.

\section{Data collection}

Data were collected from parent's/caregivers using an interview based questionnaire, that assessed sociodemographic profile (child's age and sex, parental education and occupation), previous dental visits, and oral hygiene behaviours (brushing, frequency of brushing, use of fluoridated toothpaste, parental supervision of brushing), and dietary habits (frequency of sugary snacks daily, food consistency) (21).

\section{Clinical examination}

Children were examined on either their wheelchairs, laid down flat on the examination bed, or in a knee-to-knee position depending on their age and physical condition. The examination was conducted by one examiner. During the examination procedure, 'Tell-Show-Feel and Do' technique was used with all children. Intraoral examination was done under daylight, using flat disposable mirror and blunt dental probe to assess:

(a) Caries experience; following the World Health Organization (WHO) criteria, using the dmft index for primary dentition, and dft and DMFT indices for mixed dentition. Caries was recorded at level of cavitation, teeth exhibiting white spot lesions were considered sound (23). No radiographic examination was made, due to the patients' high degree of spasticity, involuntary movements and cognitive impairment (19).

(b) Oral hygiene status; using the Simplified Oral Hygiene Index (OHI-S) given by Green and Vermilion (24), and its modification for the deciduous dentition as given by Miglani et al. (25). This index has two components, the Debris Index (DI-S) and the Calculus Index (CI-S). The examination involves the evaluation of the labial surfaces of maxillary right molar, maxillary right central incisor, maxillary left molar and mandibular left central incisor, as well as the lingual surfaces of mandibular left molar and mandibular right molar. Each surface was given a score from 0-3 for both DI-S and CI-S, based on numerical determinations representing surface area covered with soft debris and calculus. For each individual, the average score was calculated for both DI-S and CI-S indices, values from 0 -3. Then both were combined to obtain the Simplified Oral Hygiene Index score; values from 0 -6.

Training and calibration for dental caries examination were carried out in the Department of Paediatric Dentistry and Dental Public Health in Faculty of Dentistry, Alexandria University. In order to evaluate intra-examiner reproducibility, 10 cases were randomly selected and reexamined after 7-days. Kappa value for caries diagnosis was $0.91(26)$. 
Topical fluoride $(0.1 \%$ flourosilane, Fluor Defender varnish) were applied to all children, after removal of softdebri by a piece of gauze. All children were granted new toothbrushes and toothpastes, while parents were given oral hygiene and dietary instruction. Children who needed dental treatment were referred to the paediatric dental clinic in faculty of dentistry to receive required treatment under general anaesthesia.

\section{Statistical analysis}

Statistical analysis was carried out using statistical package for social sciences (SPSS for windows, version 23.0, Inc. Chicago, IL, USA). Significance level was set at the $5 \%$ level. Descriptive statistics were displayed as mean, standard deviation for quantitative variables and frequencies and percentages for qualitative variables. Previous dental visits, oral hygiene practices and dietary habits were compared between the 2 groups using chisquared test (or Fisher exact test as indicated). Oral hygiene index scores were compared using Mann-Whiney U- test. Variables which reported significant difference in the univariate analysis, were used in the multivariable linear regression model, to determine which independent variables were significant for explaining the variation in the total caries experience (dependant variable). This was calculated for both primary (dmft) and mixed dentitions (dft+DMFT) among all of children with CP in this study, either who had caries or caries free $(27,28)$. Regression coefficient, $95 \%$ confidence intervals and estimates of effect size were calculated.

\section{RESULTS}

The average age of children with CP in the study was $6.75 \pm 2.62$ years, about two thirds of them were males. Both groups were comparable as regards age and sex $(\mathrm{P}=1$ and 0.8 respectively, Table 1 ).

Socio-demographic data showed no statistically significant difference between the two groups as regards maternal education, father and mother's occupation $(\mathrm{P}=$ $0.17,0.56$ and 0.24 respectively). However, paternal education level differs significantly between the groups $(p=0.03)$, where $60 \%$ of fathers of children with CP who were caries free had completed high school. Table 2

Statistically significant poorer oral hygiene was observed in the children with CP ( $\mathrm{P}<0.0001$, table 3$)$.

More soft-debri were detected covering the teeth than calculus in both groups.

shows the differences of oral health practices between children with CP who had carious lesions (subjects) and who were caries free (controls). As reported by parents, the prevalence of dental visits during the past 12 months didn't differ between both groups $(\mathrm{P}=0.11)$. However, a difference existed regarding the reason of these visits $(\mathrm{P}=$ 0.02 ), relieving pain was the main reason in children with $\mathrm{CP}$ who had carious lesions.

Children in the control group brush their teeth as twice as children who have carious lesions, either once daily or less, however this difference wasn't statistically significant $(p=0.15)$. As regards snacking habits, sugary snacks were offered less frequently to caries free children than children in the study group $(42.5 \%, 77.5 \%, \mathrm{p}=0.001)$. Compared to children with CP who were caries free, higher percentage of children with $\mathrm{CP}$ in study group were reported to consume liquid diet (2.5\%, 37.5\%, p <0.0001). Figure 1
Table (1): Sociodemographic profile of caries and caries free children with Cerebral Palsy

\begin{tabular}{|c|c|c|c|c|}
\hline & & $\begin{array}{l}\text { Study group } \\
\text { DMF }>0 \\
(n=40)\end{array}$ & $\begin{array}{c}\text { Control group } \\
\mathrm{DMF}=0 \\
(n=40)\end{array}$ & $P$ value \\
\hline \multirow[t]{2}{*}{ Age $\dagger$} & Min- Max & $3-11$ & $3-11$ & \multirow{2}{*}{1.00} \\
\hline & Mean \pm SD & $6.75 \pm 2.62$ & $6.75 \pm 2.62$ & \\
\hline \multirow{2}{*}{ Gender § } & Male: $n(\%)$ & $27(67.5 \%)$ & $28(70.0 \%)$ & \multirow{2}{*}{0.8} \\
\hline & Female: $n(\%)$ & $13(32.5 \%)$ & $12(30.0 \%)$ & \\
\hline \multirow{4}{*}{$\begin{array}{l}\text { Father's } \\
\text { education § }\end{array}$} & Illiterate $n(\%)$ & $10(25.05 \%)$ & $5(12.5 \%)$ & \multirow{4}{*}{$0.03 *$} \\
\hline & $\begin{array}{c}\text { Primary/ } \\
\text { Preparatory } \\
\mathrm{n}(\%)\end{array}$ & $14(35.0 \%)$ & $8(20.0 \%)$ & \\
\hline & $\begin{array}{l}\text { High school } \\
\text { completed } n(\%)\end{array}$ & $11(27.5 \%)$ & $24(60.0 \%)$ & \\
\hline & $\begin{array}{l}\text { College } \\
\text { completed } n(\%)\end{array}$ & $5(12.5 \%)$ & $3(7.5 \%)$ & \\
\hline \multirow{2}{*}{$\begin{array}{l}\text { Father's } \\
\text { occupation § }\end{array}$} & $\begin{array}{c}\text { Unemployed: } n \\
(\%)\end{array}$ & $8(20.0 \%)$ & $6(15.0 \%)$ & \multirow{2}{*}{0.56} \\
\hline & Employed $n(\%)$ & $32(80.05 \%)$ & 34 (85.0\%) & \\
\hline \multirow{4}{*}{$\begin{array}{l}\text { Mother's } \\
\text { education § }\end{array}$} & Illiterate $n(\%)$ & $6(15.0 \%)$ & $9(22.5 \%)$ & \multirow{4}{*}{0.17} \\
\hline & $\begin{array}{c}\text { Primary/ } \\
\text { Preparatory } \\
\text { n(\%) }\end{array}$ & $18(45.0 \%)$ & $10(25.0 \%)$ & \\
\hline & $\begin{array}{c}\text { High school } \\
\text { completed } n(\%)\end{array}$ & $10(25.0 \%)$ & $17(42.5 \%)$ & \\
\hline & $\begin{array}{c}\text { College } \\
\text { completed } n(\%)\end{array}$ & $6(15.0 \%)$ & $4(10.0 \%)$ & \\
\hline \multirow[t]{2}{*}{$\begin{array}{l}\text { Mother's } \\
\text { occupation § }\end{array}$} & $\begin{array}{c}\text { Unemployed: } n \\
\text { (\%) }\end{array}$ & $35(87.5 \%)$ & $31(77.5 \%)$ & \multirow{2}{*}{0.24} \\
\hline & Employed $n(\%)$ & $5(12.5 \%)$ & $9(22.5 \%)$ & \\
\hline
\end{tabular}

*Statistically significant at $\mathrm{P}<0.05$.

$\dagger$ Student T test used

$\S$ Chi-squared test is used.

Table (2): Oral health practices among caries and caries free Cerebral Palsy children.

\begin{tabular}{|c|c|c|c|}
\hline & $\begin{array}{c}\text { Study group } \\
\text { DMF }>0(n=40)\end{array}$ & $\begin{array}{c}\text { Control group } \\
\mathrm{DMF}=0(n=40)\end{array}$ & $P$ value \\
\hline \multicolumn{4}{|l|}{ Dental visits } \\
\hline $\begin{array}{l}\text { Dental visit in previous } \\
\text { year } n(\%)\end{array}$ & $8(20 \%)$ & $3(7.5 \%)$ & 0.11 \\
\hline \multicolumn{4}{|c|}{ Reason of Dental visit q $\mathrm{n}(\%)$} \\
\hline For Check-up & $1(12.5 \%)$ & $3(100 \%)$ & \multirow{2}{*}{$0.02 *$} \\
\hline Relief pain & $7(87.5 \%)$ & 0 & \\
\hline \multicolumn{4}{|l|}{ B) Brushing } \\
\hline Brushing teeth $\S$ & $5(12.5 \%)$ & $10(25.0 \%)$ & 0.15 \\
\hline $\begin{array}{l}\text { Frequency of brushing } \mathbb{\Upsilon} \\
\text { - Once or more } \\
\text { - Less than once }\end{array}$ & $\begin{array}{c}0 \\
5(100 \%)\end{array}$ & $\begin{array}{l}4(40 \%) \\
6(60 \%)\end{array}$ & 0.23 \\
\hline $\begin{array}{l}\text { Child needs supervision } \\
\text { upon brushing }\end{array}$ & $5(100.0 \%)$ & $9(90.0 \%)$ & 1.00 \\
\hline $\begin{array}{l}\text { Using fluoridated tooth } \\
\text { paste }\end{array}$ & $2(40.0 \%)$ & $8(80.0 \%)$ & 0.25 \\
\hline Brushing problem $₫$ & $4(80.0 \%)$ & $6(60.0 \%)$ & 0.6 \\
\hline \multicolumn{4}{|l|}{ C) Dietary habits } \\
\hline $\begin{array}{l}\text { 1- Snaking Habit } \S \\
\text { - Twice or more daily }\end{array}$ & $31(77.5 \%)$ & 17 (42.5\%) & $0.001 *$ \\
\hline \multicolumn{4}{|l|}{ 2- Food consistency $\S$} \\
\hline - Solid & $5(12.5 \%)$ & $24(60.0 \%)$ & \multirow{3}{*}{$<0.0001^{*}$} \\
\hline - Semisolid & $20(20 \%)$ & $15(37.5 \%)$ & \\
\hline - Liquid & $15(37.5 \%)$ & $1(2.5 \%)$ & \\
\hline
\end{tabular}

*Statistically significant at $\mathrm{P}<0.05$.

$\S$ Chi-squared test is used.

IFisher exact test is used 
Table (3): Mean score of the Oral Hygiene Index (OHI-S) of caries and caries free Cerebral Palsy children

\begin{tabular}{||l|c|c|c||}
\hline & $\begin{array}{c}\text { Study group } \\
\text { DMF }>\mathbf{0} \\
(\mathbf{n}=\mathbf{4 0 )}\end{array}$ & $\begin{array}{c}\text { Control group } \\
\mathbf{D M F}=\mathbf{0} \\
\mathbf{( n = 4 0 )}\end{array}$ & P value \\
\hline $\begin{array}{c}\text { Debris index } \\
\text { (mean } \pm \text { SD) }\end{array}$ & $2.45 \pm 0.31$ & $1.48 \pm 0.19$ & $<0.0001^{*}$ \\
\hline $\begin{array}{l}\text { Calculus index } \\
\text { (mean } \pm \text { SD) }\end{array}$ & $0.26 \pm 0.28$ & $0.09 \pm 0.13$ & $0.01^{*}$ \\
\hline $\begin{array}{l}\text { OHI-S } \\
\text { (mean } \pm \text { SD) }\end{array}$ & $2.71 \pm 0.43$ & $1.57 \pm 0.26$ & $<0.0001^{*}$ \\
\hline
\end{tabular}

MWU: Mann Whitney U test

*Statistically significant at $\mathrm{P}<0.05$.

Table (4): Effect of oral health practices on the total caries experience in children with Cerebral Palsy.

\begin{tabular}{|c|c|c|c|c|c|c|}
\hline \multirow{2}{*}{\multicolumn{2}{|c|}{$\begin{array}{l}\text { Independent } \\
\text { Variables }\end{array}$}} & \multicolumn{2}{|c|}{$\begin{array}{c}\text { Univariate } \\
\text { regression } \\
\text { (unadjusted) } \\
\end{array}$} & \multicolumn{3}{|c|}{$\begin{array}{c}\text { Multivariable analysis } \\
\text { (Adjusted) }\end{array}$} \\
\hline & & \multirow{2}{*}{\begin{tabular}{|l|}
$\begin{array}{l}\text { Regression } \\
\text { coefficient } \\
(\mathbf{9 5 \%} \text { C.I) }\end{array}$ \\
-3.09 \\
$(-5.53,-0.64)$
\end{tabular}} & \multirow{2}{*}{\begin{tabular}{|l|} 
P value \\
$0.014 *$
\end{tabular}} & \multirow{2}{*}{\begin{tabular}{|c|}
$\begin{array}{l}\text { Regression } \\
\text { coefficient } \\
\text { (95\%C.I.) }\end{array}$ \\
$\begin{array}{c}-0.94 \\
(-1.95,0.07)\end{array}$
\end{tabular}} & \multirow{2}{*}{\begin{tabular}{|c|} 
P value \\
0.069
\end{tabular}} & \multirow{2}{*}{\begin{tabular}{r|}
$\begin{array}{l}\text { Partial } \\
\text { eta } \\
\text { squarec }\end{array}$ \\
0.045
\end{tabular}} \\
\hline $\begin{array}{l}\text { Dental visit } \\
\text { last year }\end{array}$ & $\begin{array}{l}\text { No vs } \\
\text { yes }\end{array}$ & & & & & \\
\hline $\begin{array}{l}\text { Brushing } \\
\text { teeth }\end{array}$ & $\begin{array}{l}\begin{array}{l}\text { No vs } \\
\text { yes }\end{array} \\
\end{array}$ & $\begin{array}{l}2.9 \\
(0.75,5.05)\end{array}$ & $0.009 *$ & $\begin{array}{c}0.19 \\
(-1.95,0.74) \\
\end{array}$ & 0.751 & 0.002 \\
\hline $\begin{array}{l}\text { Sugary } \\
\text { Snaking } \\
\text { Habit }\end{array}$ & $\begin{array}{l}\text { once vs } \\
\text { twice } \\
\text { or } \\
\text { more } \\
\text { daily }\end{array}$ & $\begin{array}{l}-3.57 \\
(-5.17,- \\
1.98)\end{array}$ & $<0.0001^{*}$ & $\begin{array}{c}0.94 \\
(0.043,1.83)\end{array}$ & $0.04 *$ & 0.056 \\
\hline \multirow[t]{2}{*}{$\begin{array}{l}\text { Food } \\
\text { consistency }\end{array}$} & $\begin{array}{l}\text { Solid vs } \\
\text { liquid }\end{array}$ & $\begin{array}{l}-7.46 \\
(-9.24,- \\
5.67)\end{array}$ & $<0.0001^{*}$ & $\begin{array}{c}-3.7 \\
(-4.88,- \\
2.66)\end{array}$ & $<0.0001^{*}$ & 0.386 \\
\hline & $\begin{array}{l}\text { Semi- } \\
\text { solid } \\
\text { vs } \\
\text { liquid }\end{array}$ & $\begin{array}{l}-4.85 \\
(-6.58,- \\
3.12)\end{array}$ & $<0.0001^{*}$ & $\begin{array}{c}-3.23 \\
(-4.17,-2.3)\end{array}$ & $<0.0001 *$ & 0.393 \\
\hline OHI-S & & $\begin{array}{l}4.97 \\
(4.3,5.64)\end{array}$ & $<0.0001^{*}$ & $\begin{array}{r}4.45 \\
(3.75, \\
5.14)\end{array}$ & $<0.0001 *$ & 0.691 \\
\hline
\end{tabular}

$\mathrm{F}=77.1, \mathrm{p}<0.0001^{*}$, Adjusted R Squared $=0.85$

* statistically significant at $\mathrm{P}<0.05$.

The model is adjusted for the sociodemographic factors.

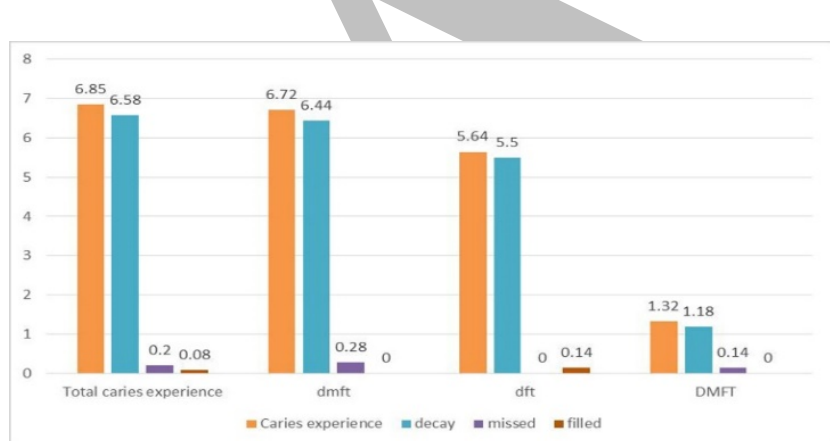

Figure (1): Caries experience among group of children with Cerebral Palsy in Alexandria.

\section{DISCUSSION}

Dental caries is consistently reported as one of the primary medical needs of children with CP $(7,19)$. Although the role of oral health behaviours in maintaining good oral health is widely recognized, few studies in the literature discussed this issue among special health care groups $(21,29)$. The present study was designed to investigate the association of oral health behaviours on dental caries experience among children with CP in Alexandria. The results support the hypothesis that differences could exist between children with Cerebral Palsy who had caries and who were caries free, regarding the oral health behaviours.

The mean values of dmft, dft and DMFT were 6.72 \pm 2.52, $5.64 \pm 2.98$ and $1.32 \pm 1.73$, respectively. Caries experience in permanent teeth was much less than in the primary teeth in mixed dentition, this could be explained as the exposure time for permanent teeth to cariogenic factors is much less to induce the development of cavitated dentinal lesions (30). Caries in primary teeth (dmft) was higher than previous findings reported in children with $\mathrm{CP}$ in Brazil $2.22 \pm 3.23$ (11), China $4.81 \pm 11.24(7)$ and Turkey $1.40 \pm 1.52(31)$. However, it is considered much less than caries experience reported in Saudi Arabia 18.8 $\pm 16.3(27)$. The mean value of DMFT was comparable to that of Brazilian children $1.71 \pm 2.42$ (11). These divergences could be due to variations in the age, sample size or selection methods.

The untreated caries was the major contributor in caries experience in the primary and mixed dentitions (87\%), in similarity to previous reports in CP children $(10,27,32)$. This could be a reflection for poor dental awareness and lack of dental healthcare access for children with special needs. Waldman \& Perman attributed this problem to the fact that dentists are not fully integrated into the interdisciplinary health care team assisting $\mathrm{CP}$ patients, and that the syllabus of dental schools usually does not provide adequate experience for managing patients with disabilities (33).

Dental attendance was particularly poor among children with CP regardless of the caries activity, about one fourth of the sample population had visited the dentist during the past 12 months. Furthermore, the main reason for these visits was predominantly problem/ treatment -related. Similar attitude was reported by Rennan Y. Du in China (21) and De Camargo et al (10). This situation could be explained by the fact that oral health care needs of children with CP have to compete with their other health care needs (9). It is important to promote regular dental attendance and dental check-up among caregivers, to aid in early prevention of oral diseases and reduce the burden on their caregivers (22).

There was no difference regarding the prevalence and frequency of toothbrushing between cases and control groups. However, only small percentage of the whole sample (20\%) reported tooth brushing, mainly less than once daily. This value was much less than comparable groups in other countries (11), and did not meet the recommended guidelines by the American Academy of Paediatric Dentistry for children with special needs (34). It was noticed that most of caregivers of children with CP in both groups frequently assisted their children in tooth brushing. Such practice of brushing should be encouraged and widely recommended, as children in general, and especially those with CP do not have the dexterity to brush adequately.

Unfavourable dietary habits including more frequent consumption of sugary snacks and liquid diet, were found to be significantly associated with higher total DMF scores in the present study. This agrees with most findings in the literature $(19,35)$. Children with CP often require high calorie supplementary feeding to maintain body weight, since they have reduced control of gastrointestinal mobility resulting in malnutrition (36). These supplements are high in extrinsic sugars that would have a deleterious effect on 
oral health (37). Therefore, timely nutritional rehabilitation and preventive measures in oral health may significantly improve the quality of life of these individuals.

The level of oral hygiene status reflects the efficiency and frequency of brushing and possibly of dietary habits. Poor oral hygiene is considered the main factor associated with caries experience in children with $\mathrm{CP}$ in the present study. This finding is in accordance with previously reported data by Roberto (16), and Alhammad (27), who stated that the level of oral hygiene perceived on the first appointment in children with CP was the only factor associated with DMF scores.

Achievement and maintaining optimal oral hygiene is a specific problem in this population. The unsatisfactory oral hygiene could be referred to many factors, including impaired manual dexterity which results in their inability to manipulate a tooth brush (38). Alterations in sensation, cognition, commination and behaviour are common findings (39), causing partial or total reliance on the caregiver to perform daily activities, such as feeding, mobility, general hygiene and oral hygiene (40). Whereas, increased intra-oral sensitivity and the presence of pathologic oral reflexes (biting and vomiting) may also complicate the condition, as poorly controlled use of a toothbrush or floss could result in gagging or vomiting (6, 41).

The present study emphasises the importance of introducing educative/ preventive measures for children with $\mathrm{CP}$ as soon as their condition is diagnosed to improve the general and oral health of these children. This may include motivation of caregivers with regard to an adequate level of daily oral hygiene practices. Ideally, an individualized hygiene plan should be designed for each patient.

One of the limitation of the study was that the examiner was not blinded. The potential for recall bias is considered the main threat to case-control studies since information was obtained about past exposures that may not be accurately remembered. However, most of the mothers had no difficulty in recalling the required information.

\section{CONCLUSION}

The results of this study show that the level of oral hygiene status reflecting the efficiency of oral health behaviours, is considered the main factor associated with caries experience in children with CP. However, eating solid food and less than two sugary snacks per day were considered caries protective factors.

\section{CONFLICT OF INTEREST}

The authors declare that they have no conflicts of interest.

\section{REFERENCES}

1. Dougherty NJ. A review of cerebral palsy for the oral health professional. Dent Clin N Am. 2009;53:329-38.

2. McManus V, Guillem P, Surman G, Cans C. SCPE work, standardization and definition--an overview of the activities of SCPE: a collaboration of European CP registers. Chinese journal of contemporary pediatrics. 2006;8:261-5.

3. Oskoui M, Coutinho F, Dykeman J, Jette N, Pringsheim T. An update on the prevalence of cerebral palsy: a systematic review and meta-analysis. Developmental medicine and child neurology. 2013;55:509-19.

4. Koman LA, Smith BP, Shilt JS. Cerebral palsy. Lancet. 2004;363:1619-31.

5. Jacobsson B, Hagberg G. Antenatal risk factors for cerebral palsy. Best Pract Res Clin Obstet Gynaecol. 2004;18:425-36.

6. Santos MT, Masiero D, Novo NF, Simionato MRL. Oral conditions in children with cerebral palsy. J Dent Child. 2003;70:40-6.

7. Du RY, McGrath C, Yiu CK, King NM. Oral health in preschool children with cerebral palsy: a case-control community-based study. Int J Paediatr Dent. 2010;20:3305.

8. Lin X, Wu W, Zhang C, Lo EC, Chu CH, Dissanayaka WL. Prevalence and distribution of developmental enamel defects in children with cerebral palsy in Beijing, China. Int J Paediatr Dent. 2011;21:23-8.

9. Stevanović R, Jovicić O. Oral health in children with cerebral palsy. Srp Arh Celok Lek. 2004;132:214-8.

10. De Camargo MAF, Antunes JLF. Untreated dental caries in children with cerebral palsy in the Brazilian context. Int J Paediatr Dent. 2008;18:131-8.

11. Cardoso AM, Gomes LN, Silva CRD, Soares RdS, de Abreu MHN, Padilha WW, et al. Dental caries and periodontal disease in Brazilian children and adolescents with cerebral palsy. Int J Environ Res Public Health. 2014;12:335-53.

12. Jaber M A , Allouch T. Dentofacial Abnormalities and Oral Health Status in Children with Cerebral Palsy. J Interdiscipl Med Dent Sci. 2015:163-4.

13. Nielsen LA. Caries among children with cerebral palsy: relation to CP-diagnosis, mental and motor handicap. ASDC journal of dentistry for children. 1990;57:267-73.

14. Pope J, Curzon M. The dental status of cerebral palsied children. Pediatr Dent. 1991;13:156-62.

15. Holst D. Causes and prevention of dental caries: a perspective on cases and incidence. Oral Health Prev Dent. 2005;3:9-14.

16. Roberto LL, Machado MG, Resende VL, Castilho LS, Abreu MH. Factors associated with dental caries in the primary dentition of children with cerebral palsy. Brazilian oral research. 2012;26:471-7.

17. Fejerskov O. Changing paradigms in concepts on dental caries: consequences for oral health care. Caries research. 2004;38:182-91.

18. Nallegowda M, Mathur V, Singh U, Prakash H, Khanna M, Sachdev G, et al. Oral health status in Indian children with cerebral palsy-A pilot study. Ind J PMR. 2005;16:14.

19. Santos MT, Guare RO, Celiberti P, Siqueira WL. Caries experience in individuals with cerebral palsy in relation to oromotor dysfunction and dietary consistency. Spec Care Dentist. 2009;29:198-203.

20. Liu Z, Yu D, Luo W, Yang J, Lu J, Gao S, et al. Impact of oral health behaviors on dental caries in children with intellectual disabilities in Guangzhou, China. Int J Environ Res Public Health. 2014;11:11015-27.

21.Du RY, McGrath CP, Yiu CK, King NM. Oral health behaviors of preschool children with cerebral palsy: a casecontrol community-based study. Special Care in Dentistry. 2014;34:298-302. 
22. Santos MT, Biancardi M, Guare RO, Jardim JR. Caries prevalence in patients with cerebral palsy and the burden of caring for them. Spec Care Dent. 2010;30:206-10.

23. World Health Organization. Oral health surveys: basic methods. 5th ed. Geneva: WHO: World Health Organization; 2013.

24. Greene JG, Vermillion JR. The simplified oral hygiene index. J Am Dent Assoc. 1964;68:7-13.

25. Miglani D, Beal J, James P, Behari S. The assessment of dental cleanliness status of the primary dentition using a modification of the simplified oral hygiene index (OHISM). J Indian Dent Assoc. 1973;45:385-8.

26. McHugh ML. Interrater reliability: the kappa statistic. Biochemia Medica. 2012;22:276-82.

27. Alhammad NS, Wyne AH. Caries experience and oral hygiene status of cerebral palsy children in Riyadh. Tropical dental journal. 2010;33:5-9.

28. Shaffer JR, Leslie EJ, Feingold E, Govil M, McNeil DW, Crout RJ, et al. Caries experience differs between females and males across age groups in Northern Appalachia. Int J Dent. 2015; 2015: 1-8. Doi: 10.1155/2015/938213.

29. Jaccarino J. Helping the special needs patient maintain oral health. Dental assistant. 2009;78:11-2.

30. Doneria D, Thakur S, Singhal P, Chauhan D, Jayam C, Uppal A. Comparative evaluation of caries status in primary and permanent molars in 7-8-year-old schoolchildren of shimla using caries assessment spectrum and treatment index. Contemporary clinical dentistry. 2017;8:128-133.

31. Altun C, Guven G, Akgun OM, Akkurt MD, Basak F, Akbulut E. Oral health status of disabled individuals attending special schools. European journal of dentistry. 2010;4:361-6.

32. Guaré RO, Ciamponi A. Dental caries prevalence in the primary dentition of cerebral-palsied children. J Clin Pediatr Dent 2003;27:287-92.

33. Waldman H, Perlman S. Children with disabilities are aging out of dental care. J Dent Child. 1997;64:385-90.

34. Dentistry AAOP. Guideline on management of dental patients with special health care needs. Pediatric dentistry. 2012;34:160-5.

35. Pradhan A, Slade GD, Spencer AJ. Factors influencing caries experience among adults with physical and intellectual disabilities. Community Dent and Oral Epidemiol. 2009;37:143-54.

36. Sullivan PB. Gastrointestinal disorders in children with neurodevelopmental disabilities. Dev Disabil Res Rev. 2008;14:128-36.

37. Masson LF, Blackburn A, Sheehy C, Craig LC, Macdiarmid JI, Holmes BA, et al. Sugar intake and dental decay: results from a national survey of children in Scotland. Brit J Nutr. 2010;104:1555-64.

38. Molin I, Alricsson M. Physical activity and health among adolescents with cerebral palsy in Sweden. Int J Adolesc Med Health 2009;21:623-33.

39. Bax M, Goldstein M, Rosenbaum P, Leviton A, Paneth N, Dan B, et al. Proposed definition and classification of cerebral palsy, April 2005. Dev Med Child Neurol. 2005;47:571-6.
40. Abanto J, Ortega AO, Raggio DP, Bönecker M, Mendes FM, Ciamponi AL. Impact of oral diseases and disorders on oral-health-related quality of life of children with cerebral palsy. Special Care in Dentistry. 2014;34:56-63.

41. Santos MT, Nogueira M. Infantile reflexes and their effects on dental caries and oral hygiene in cerebral palsy individuals. J Oral Rehabil 2005;32:880-5. 